
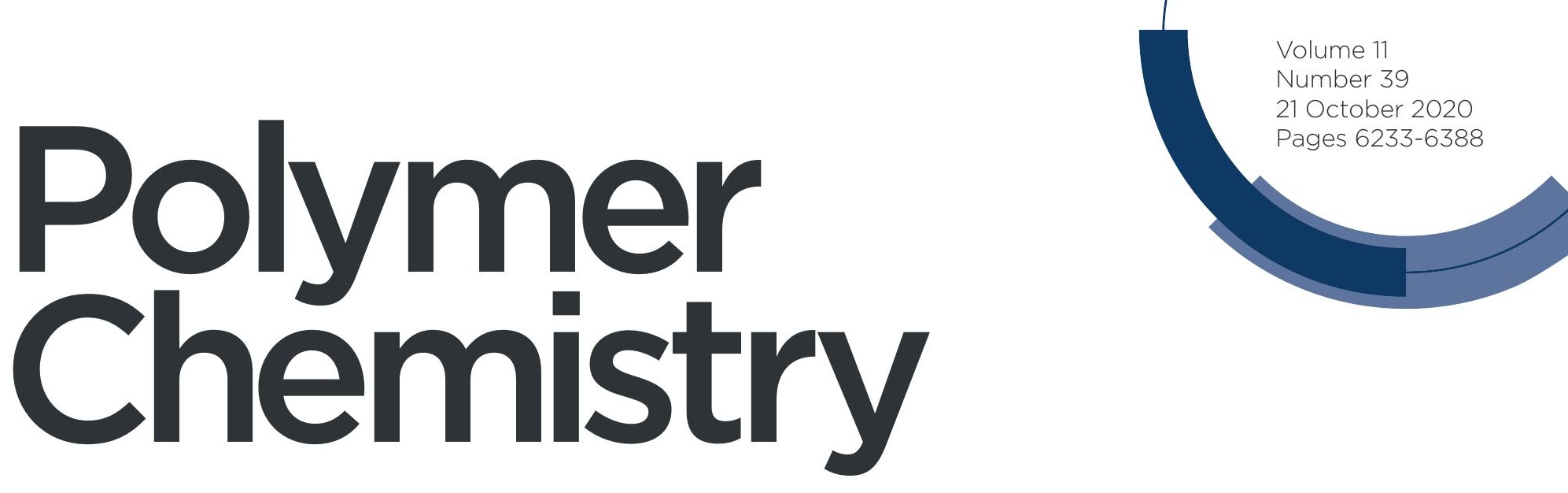

rsc.li/polymers

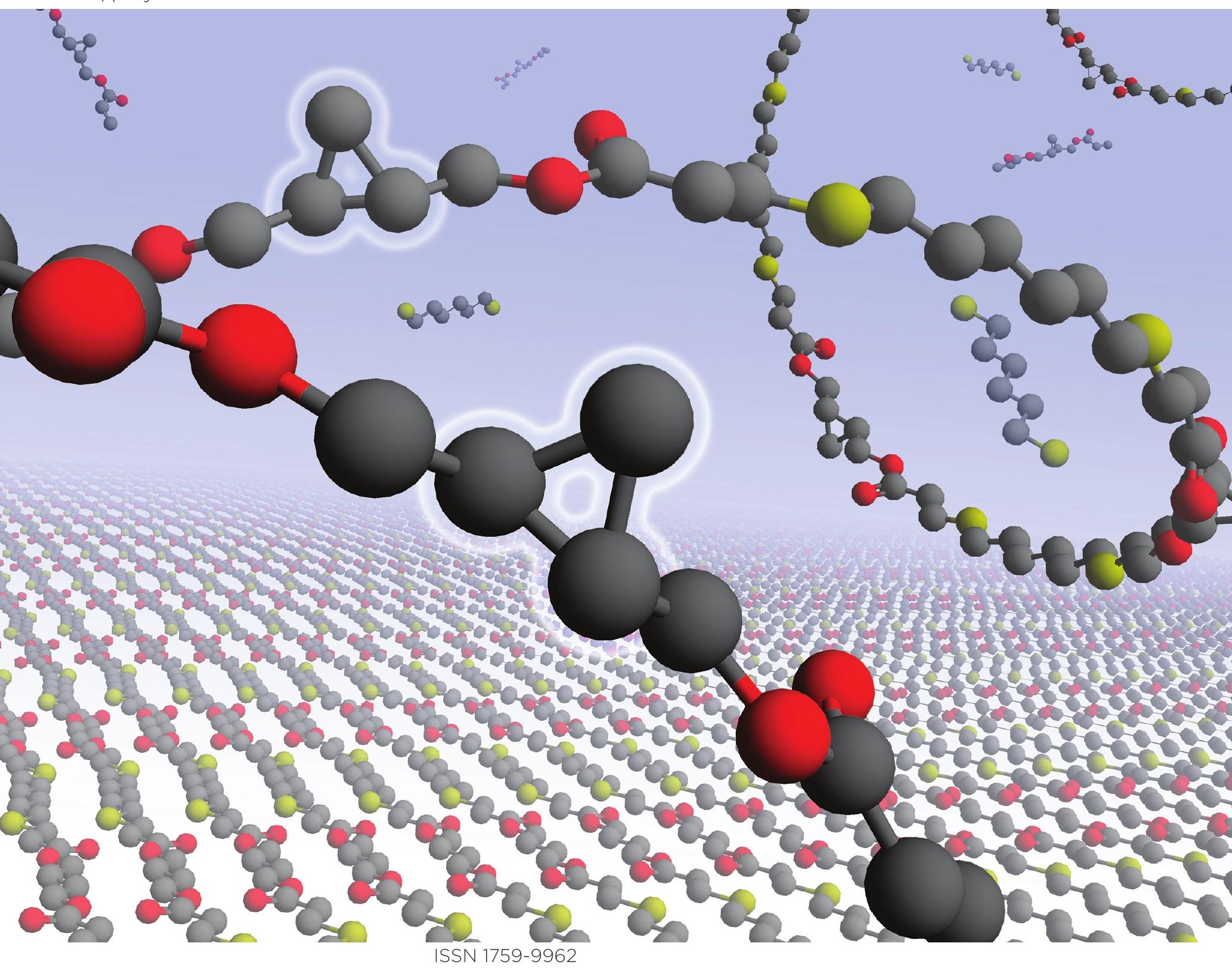




\section{(A) Check for updates}

Cite this: Polym. Chem., 2020, 11 6251

Received 14th July 2020,

Accepted 28th August 2020

DOI: 10.1039/d0py01004a

rsc.li/polymers

\title{
Understanding structure-property relationships of main chain cyclopropane in linear polyesters $\uparrow$
}

\begin{abstract}
Connor J. Stubbs and Andrew P. Dove (D) *
Rigid ring structures have gained increasing interest in the polymer materials community as an effective means to manipulate bulk properties. Despite this, little work has focussed on the smallest ring: cyclopropane. Herein, we report a polymerisation that enables incorporation of stereopure cis and trans 1,2-cyclopropanedimethanol through the thiol-Michael "click" reaction between dithiol and diacrylate monomers. Polyesters containing a cyclopropane backbone were found to be amorphous, whilst comparable polymers with a 1,4-butanediol backbone were semi-crystalline. By copolymerising cyclopropane monomers at varying ratios with 1,4-butanediol monomers, the crystalinity of the resulting polymer could be effectively tuned. Successfully adjusting the resulting crystallinity resulted in control over the ultimate tensile strength (UTS) and the Young's modulus (E) of the material. Generally, it was found that increasing cyclopropane content led to a decreased UTS and $E$ as a result of lower polymer crystalinity. Effects of cyclopropane stereochemistry on thermomechanical properties were found to be minimal at low cyclopropane backbone ratios.
\end{abstract}

\section{Introduction}

Conformationally-locked ring structures have recently garnered considerable attention in the design of new thermoplastic materials. ${ }^{1-3}$ This derives from the ability to manipulate and predict bulk properties from their incorporation into linear polymer systems. Typically, property manipulation is achieved by altering functionalities within a polymer, which can require synthetically demanding steps. Conformationally locked rings offer simple and convenient control of bulk properties in linear polymers. Hence, continual understanding into the influence of rigid ring structures on the thermomechanical properties of the resultant polymers is vital to designing the next generation of high-performance materials.

Oil-sourced cyclohexylene rings have been extensively investigated in various thermoplastic systems, including polyesters, polyamides and polycarbonates. ${ }^{3-6}$ By incorporating and controlling the ratios of cyclohexane units in polymers, numerous bulk properties can be manipulated. For example, the ratio of 1,4-cyclohexanedimethanol in polymer materials has been reported to impact bulk properties such as glass transition temperature $\left(T_{\mathrm{g}}\right)$, bulk crystallinity, tensile strength and gas permeability. ${ }^{7-9}$ More recently bio-based bicyclic diols have gained significant attention in thermoplastic polymers. ${ }^{10-13}$

School of Chemistry, University of Birmingham, Birmingham, B15 2TT, UK.

E-mail:a.dove@bham.ac.uk

$\dagger$ Electronic supplementary information (ESI) available: NMR spectra and thermomechanical characterisation data included. See DOI: 10.1039/d0py01004a
Wang and co-workers reported that incorporation of isosorbide, a simple isohexide unit, in polyesters led to a higher $T_{\mathrm{g}}$ and lower polymer crystallinity. ${ }^{14}$ Increasing isosorbide content also correlated with the speed at which hydrolytic degradation occurred. ${ }^{15}$

An additional structural feature to these ring systems is stereochemistry. Most rigid rings, including isohexides and cyclohexylenes, are geometrically locked which gives rise to multiple stereoisomers. There has been a recent surge in interest in leveraging stereochemistry in linear polymers to alter bulk properties. ${ }^{16}$ The stereochemical contribution of isohexides and cyclohexylene in polymer backbones has already been briefly investigated. ${ }^{8,17}$ Nevertheless, further investigation in the influence of stereochemistry on the physical and mechanical properties of the resultant materials remains a requirement for future polymer systems containing ring structures.

Despite the recent attention into cyclic structures in polymer materials, there lacks considerable investigation into the smallest cycle, cyclopropane. Previous works have focussed on cyclopropane within the polymer side chains. ${ }^{18}$ This is typically achieved via post-polymerisation modification of unsaturated polymers with diazo species. ${ }^{19}$ Mecking and co-workers have demonstrated that an increase in the side chain cyclopropane content within polybutadiene led to a higher $T_{\mathrm{g}}$ and a decrease in bulk crystallinity. ${ }^{20}$ Whilst this effectively manipulated thermal properties, the focus was on side chain functionality. As a result of this, the architectural and stereochemical influence that could have resulted from main chain cyclopropane was not examined. 
Few studies have focussed on cyclopropane in the main chain of the polymer. One notable example from Takao and co-workers demonstrated the synthesis of a range of polyesters, polyamides and polyurethanes containing cyclopropane in the main chain. ${ }^{21}$ Di-functional 1,2-cyclopropanes were synthesised and subsequently polymerised; initial observations suggested that these polymers could be compressed into freestanding films. However, no further analysis was carried out. An extensive study into cyclopropane-containing polymers is needed to further our understanding of the 3-membered structure.

Herein, we present a study into the thermomechanical properties of polyesters containing main chain cyclopropane. Polymers are synthesised in step-growth fashion using mild thiol-Michael addition between multiple dithiols and cyclopropane diacrylate monomers. The effect of stereochemistry in the chain is also investigated.

\section{Results and discussion}

In order to fully understand how cyclopropane units in the polymer main chain affects bulk properties, both cis and trans stereoisomers need to be examined independently to elucidate the stereochemical contribution. Stereopure cis and trans 1,2cyclopropane were obtained from established literature procedures (Fig. S1 $\dagger$ ). ${ }^{22}$ The diols were functionalised with acryloyl chloride to afford diacrylate-containing monomers: $\mathbf{C y}$ (trans) and $\mathbf{C y}$ (cis) (Fig. S1†). An additional commercially available diacrylate monomer, 1,4-butanedioldiacrylate (BD), was also used to serve as a linear comparison to the cyclopropanecontaining polymers. Nucleophilic thiol-Michael addition was selected because the mild and efficient conditions can afford high molecular weight polymers without causing isomerisation or other potential side reactions. ${ }^{23,24} \mathrm{~A}$ range of polyesters were synthesised from the diacrylate monomers through a phosphine catalysed polyaddition with commercially available dithiols (Scheme 1, Table 1).

Initial polymerisations used 1,6-hexanedithiol (HDT) with the three diacrylate monomers (BD, $\mathbf{C y}($ cis $)$ and $\mathbf{C y}($ trans $))$ to produce comparable homopolymers. Relatively high molecular

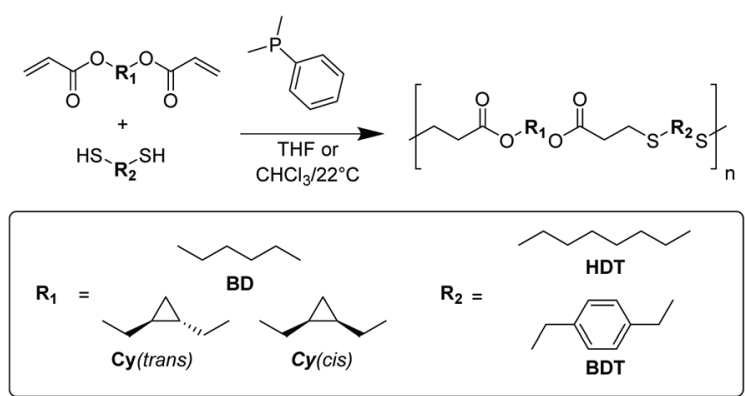

Scheme 1 General scheme for linear polyesters synthesised from phosphine-catalysed thiol-Michael addition of diacrylate and dithiol monomers.
Table 1 Characterisation of linear polyesters

\begin{tabular}{llllll}
\hline & $\begin{array}{l}M_{\mathrm{w}}{ }^{a} \\
(\mathrm{kDa})\end{array}$ & $\emptyset_{\mathrm{M}}{ }^{a}$ & $\begin{array}{l}T_{\mathrm{g}}{ }^{b} \\
\left({ }^{\circ} \mathrm{C}\right)\end{array}$ & $\begin{array}{l}\Delta H_{\mathrm{m}}{ }^{b} \\
\left(\mathrm{~J} \mathrm{~g}^{-1}\right)\end{array}$ & $\begin{array}{l}T_{\mathrm{d}, 5 \%}{ }^{c} \\
\left({ }^{\circ} \mathrm{C}\right)\end{array}$ \\
\hline Cy(trans)-co-HDT & 38.0 & 4.30 & -52 & - & 276 \\
Cy $($ cis $)$-co-HDT & 37.4 & 4.08 & -47 & - & 293 \\
BD-co-HDT & 52.7 & 3.13 & -66 & -64.0 & 315 \\
Cy $($ trans $)$-co-BDT & 23.5 & 6.58 & -17 & - & 256 \\
BD-co-BDT & 22.0 & 7.78 & -27 & -58.7 & 273
\end{tabular}

${ }^{a} M_{\mathrm{W}}$ and $\bigoplus_{\mathrm{M}}$ were determined by size exclusion chromatography (THF, $2 \% \mathrm{v} / \mathrm{v} \mathrm{NEt}_{3}$ ) analysis against polystyrene (PS) standards. ${ }^{b}$ Glass transition temperature obtained from second heating scan. Total enthalpy of melting calculated from integration of all melt transitions. ${ }^{c}$ Temperature after $5 \%$ weight loss obtained from thermogravimetric analysis.

weights were achieved $\left(35 \mathrm{kDa}<M_{\mathrm{w}}\right.$ ) that possessed modest dispersities (4.5 $>\emptyset_{\mathrm{M}}$, Table 1 ). ${ }^{1} \mathrm{H}$ NMR spectroscopy confirmed the reaction conditions had not impacted the stereochemistry or cyclopropane structure of the resulting polymers (Fig. 1a). Most noticeably, the polymers displayed vastly different physical appearances. Both cyclopropane polyesters (Cy)(trans)-co-HDT and Cy(cis)-co-HDT) were translucent and possessed a tacky consistency, even after aging for multiple

(a)
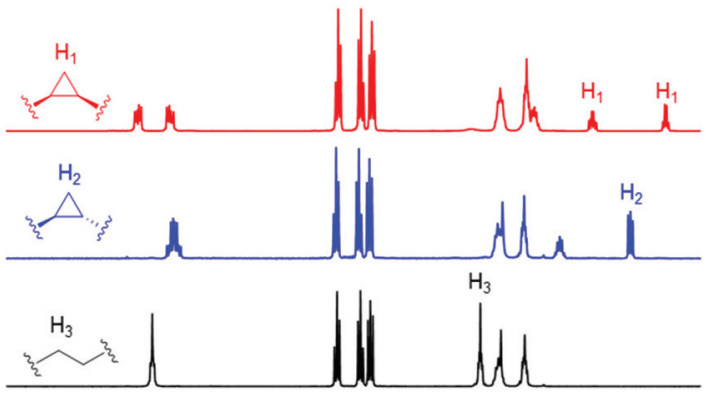

5

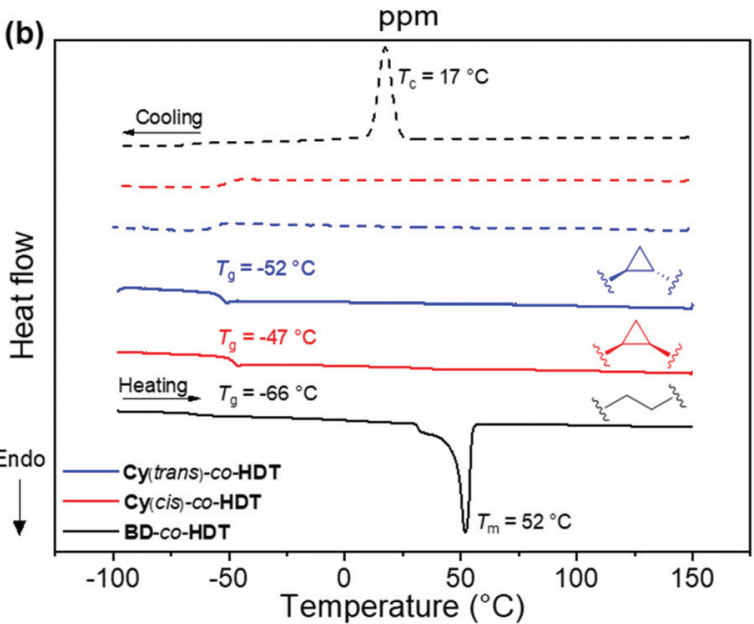

Fig. 1 (a) ${ }^{1} \mathrm{H}$ NMR spectra of polymers synthesised using HDT in $\mathrm{CDCl}_{3}$ (400 MHz, 298 K) (b) normalised DSC thermograms of polymers synthesised using HDT at a heating and cooling rate of $10 \mathrm{~K} \mathrm{~min}^{-1}$ (solid line = heating run, dashed line = cooling run). 
months at benchtop conditions. Whilst the linear control (BDco-HDT) was an opaque white solid. This observation indicated that the cyclopropane structure had significantly impacted bulk properties: crystallinity in particular.

To quantify the thermal properties and gain insight into the crystallinity, differential scanning calorimetry (DSC) was performed (Fig. 1b). The $T_{\mathrm{g}} \mathrm{s}$ of all the polymers were well below ambient temperature $\left(-66\right.$ to $\left.-47^{\circ} \mathrm{C}\right)$. There was a small deviation in the $T_{\mathrm{g}}$ observed between the cis and trans cyclopropane polyesters, where $\mathbf{C y}($ cis $)$-co-HDT had a $T_{\mathrm{g}} 5{ }^{\circ} \mathrm{C}$ higher than $\mathbf{C y}$ (trans)-co-HDT. This could be ascribed to a higher free volume in $\mathbf{C y}$ (trans)-co-HDT caused by the trans isomer. Copolymer BD-co-HDT had the lowest $T_{\mathrm{g}}$ which is attributed to more efficient chain packing of the butyl-group in comparison to the cyclopropane ring. However, the most striking observation from the DSC thermograms was the lack of melt transitions $\left(T_{\mathrm{m}}\right)$. Both cyclopropane-containing polyesters lacked a melt transition, while BD-co-HDT possessed a sharp melting peak at $52{ }^{\circ} \mathrm{C}$. This indicates that the cyclopropane polymers are amorphous whereas BD-co-HDT is crystalline, which is in agreement with the observed physical differences. It was clear that the irregularity of the cyclopropane structure had inhibited chain alignment and, therefore, negated any possible crystallisation that would have otherwise occurred. Consequently, the polymers produced were excessively tacky and unable to produce free-standing films.

In attempts to produce a polymer suitable for heat-pressing and forming a stable film, a rigid aromatic dithiol was used as comonomer. 1,4-Benzenedimethanethiol (BDT) was reacted with the diacrylate monomers, $\mathbf{C y}$ (trans) and BD. The polymerisation produced polyesters of a notably lower $M_{\mathrm{w}}$ and higher $\emptyset_{\mathbf{M}}$ than the previously synthesised polymers. A similar physical difference was observed in this aromatic system in comparison to the HDT polymers: $\mathbf{C y}($ trans $)$-co-BDT produces a tacky texture whilst BD-co-BDT system produces an opaque white solid (Fig. 2a). It was observed that the BD-co-BDT visibly changed over the course of $\sim 12 \mathrm{~h}$ at room temperature after melting which was hypothesised to be slow crystallisation. In efforts to produce comparable data, both polymers were melted until liquid-like flow was achieved $\left(\sim 100{ }^{\circ} \mathrm{C}\right)$ then cooled to room temperature $\left(22^{\circ} \mathrm{C}\right)$ and annealed in a thermostated incubator at $22^{\circ} \mathrm{C}$ for $48 \mathrm{~h}$. DSC was then performed on the annealed polymers to elucidate the thermal properties (Fig. 2b).

Both Cy(trans)-co-BDT and BD-co-BDT polymers possessed a higher $T_{\mathrm{g}}\left(-17\right.$ and $-27{ }^{\circ} \mathrm{C}$ respectively) than the previous HDT system, which was expected as a consequence of increased planarity and rigidity. It was also evident that $\mathbf{C y}$ (trans)-co-BDT had a higher $T_{\mathrm{g}}$ than BD-co-BDT resulting from the increased rigidity of the cyclopropane ring. The physical appearances of these polymers were further corroborated by the DSC thermograms. BD-co-BDT possessed multiple melt transitions which indicates that the material has multiple crystalline domains. ${ }^{25}$ Interestingly there was also an absence of a crystallisation peak $\left(T_{\mathrm{c}}\right)$ in BD-co-BDT, which we attributed to inefficient crystallisation under cooling run conditions. This corroborates the slow
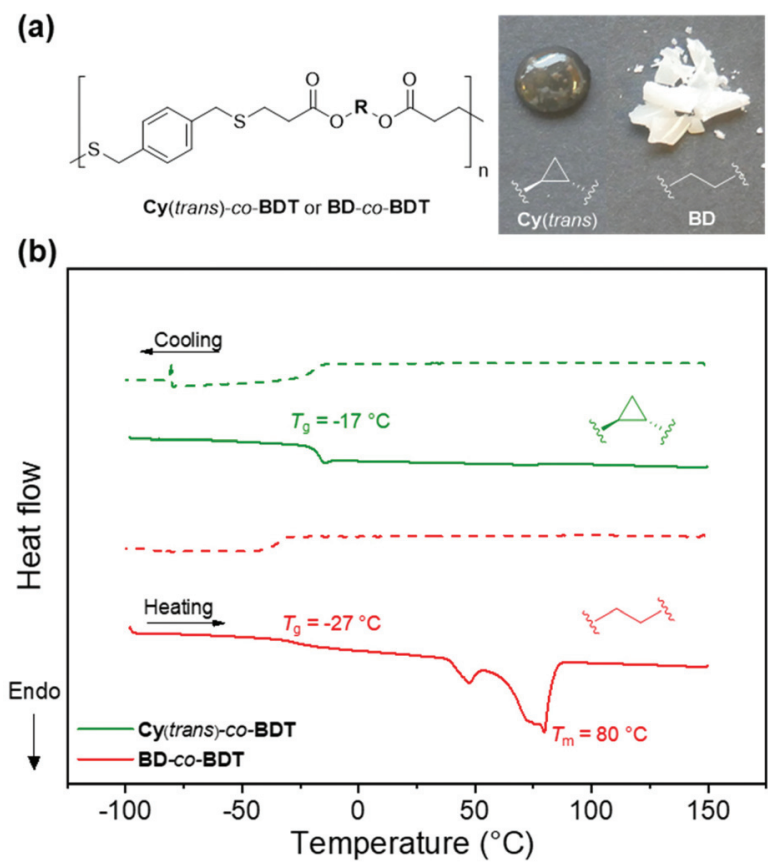

Fig. 2 (a) Polyester architecture with variable structure from diacrylate monomer with BDT. Image of annealed polyesters illustrating differences in physical appearance (b) normalised DSC thermograms of 2 day-annealed polymers made using BDT at a heating and cooling rate of $10 \mathrm{~K} \mathrm{~min}^{-1}$ (solid line = heating run, dashed line = cooling run).

physical change to a white solid observed after melting. In contrast, the Cy(trans)-co-BDT does not display a $T_{\mathrm{m}}$ peak, indicative of an amorphous polymer. Despite the higher chain ordering promoted by BDT's planarity, Cy(trans)-co-BDT was unable to produce a free-standing film. This has further demonstrated the lack of chain-packing, and subsequent crystallisation in polymers that contain the cyclopropane structure. We postulate that the geometry of 1,2-cyclopropanes can prevent packing in two ways: (i) the rigidity of the ring prevents the rotation and flexibility that aids chain packing and (ii) the 1,2substitution of the rigid cyclopropane geometry induces a "kink" in the linear chain that further disadvantages facile chain packing and hence crystallisation.

In order to create cyclopropane-containing polymers that could be processed into a flexible free-standing film, we leveraged the efficient thiol-ene polyaddition to introduce cyclopropane units into BD-containing copolymers. By polymerising BD and Cy monomers with HDT, random copolymers could be accessed. Additionally, this method allowed total control over the backbone content through varying monomer ratios within the feedstock (Scheme 2).

The three copolymerised polyesters were of comparable $M_{\mathrm{w}}$ (63.5 to $91.8 \mathrm{kDa})$ and $\bigoplus_{\mathrm{M}}(4.28$ to 4.62 , Table 2$) .{ }^{1} \mathrm{H}$ NMR spectroscopic analysis indicated that the initial feed ratio of the monomers had been successfully translated into the resulting polymers (ESI $\dagger$ ). By keeping the cyclopropane content in the polymer low $(<30 \%)$, the polymers could be heat-pressed to produce non-tacky free-standing films. It was noted that some 

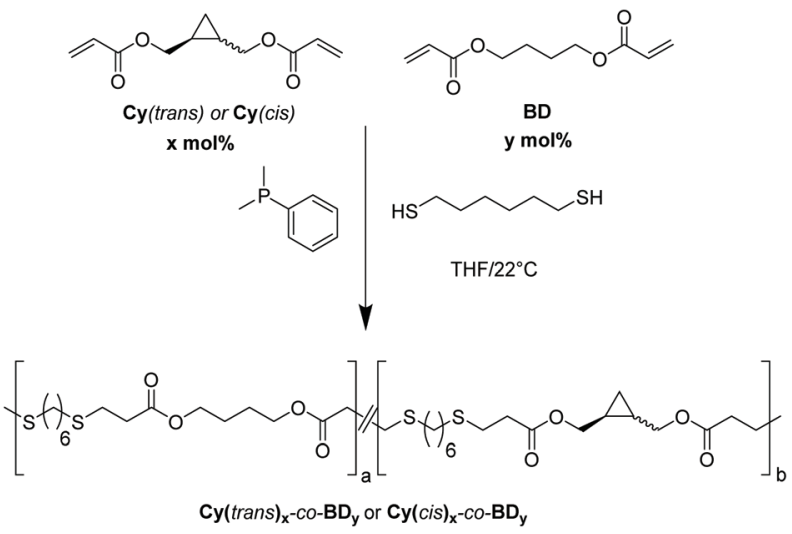

Scheme 2 Scheme illustrating the co-polymerisation of cyclopropane diacrylates and 1,4-butanediol diacrylate (BD) with 1,6-hexanedithiol (HDT) to create random co-polymers.

Table 2 Characterisation table of random copolymers containing cyclopropane

\begin{tabular}{lllll}
\hline & $M_{\mathrm{w}}{ }^{a}(\mathrm{kDa})$ & ${D_{\mathrm{M}}}^{a}$ & $T_{\mathrm{g}}{ }^{b}\left({ }^{\circ} \mathrm{C}\right)$ & $T_{\mathrm{d}, 5 \%}{ }^{c}\left({ }^{\circ} \mathrm{C}\right)$ \\
\hline $\mathrm{BD}_{90} \mathrm{Cy}(\text { trans })_{10}-$ co-HDT & 63.5 & 4.28 & -64 & 315 \\
$\mathrm{BD}_{90} \mathrm{Cy}(\text { cis })_{10}-\mathrm{Co}-\mathrm{HDT}$ & 76.9 & 4.62 & -63 & 314 \\
$\mathrm{BD}_{75} \mathrm{Cy}(\text { trans })_{25}-$ co-HDT & 91.8 & 4.54 & -62 & 313
\end{tabular}

${ }^{a} M_{\mathrm{w}}$ and $\emptyset_{\mathrm{M}}$ were determined by size exclusion chromatography (THF, $2 \% \mathrm{v} / \mathrm{v} \mathrm{NEt}_{3}$ ) analysis against polystyrene (PS) standards. ${ }^{b}$ Glass transition temperature obtained from second heating scan. ${ }^{c}$ Temperature after $5 \%$ weight loss obtained from thermogravimetric analysis.

of the films visibly became more opaque and stiffer at room temperature $\left(22^{\circ} \mathrm{C}\right)$ a few hours after heat-pressing; particularly polymers containing cyclopropane. This was attributed to slow crystallisation. Therefore, to ensure the polymers had reached thermal equilibrium and were comparable, they were heat-pressed and annealed for 2 days at $22{ }^{\circ} \mathrm{C}$ in a thermostated incubator. These samples were then characterised by uniaxial tensile testing until breakage (Fig. 3).

The newly synthesised random co-polymers were compared alongside BD-co-HDT to assess the impact cyclopropane had on tensile properties. All the samples displayed tensile curves that are consistent with a tough thermoplastic and possessed a similar strain at break (Table S1 ). All samples also displayed periodic drops in stress which was most apparent in BD-coHDT. This is characteristic of stress-oscillation behaviour observed in numerous polymer systems, however origins of this phenomenon are often disputed. ${ }^{26,27}$ A possible explanation is the formation of "voids" in the amorphous regions during elongation which leads to a stress drop and the reorientation of polymer crystallites leading to a stress

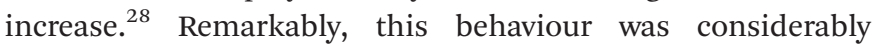
reduced in samples containing cyclopropane. This is attributed to a reduction in chain packing caused by the cyclopropane geometry, and subsequent impact on the size and spacing between the crystallites which are typically responsible for stress-oscillation behaviour.

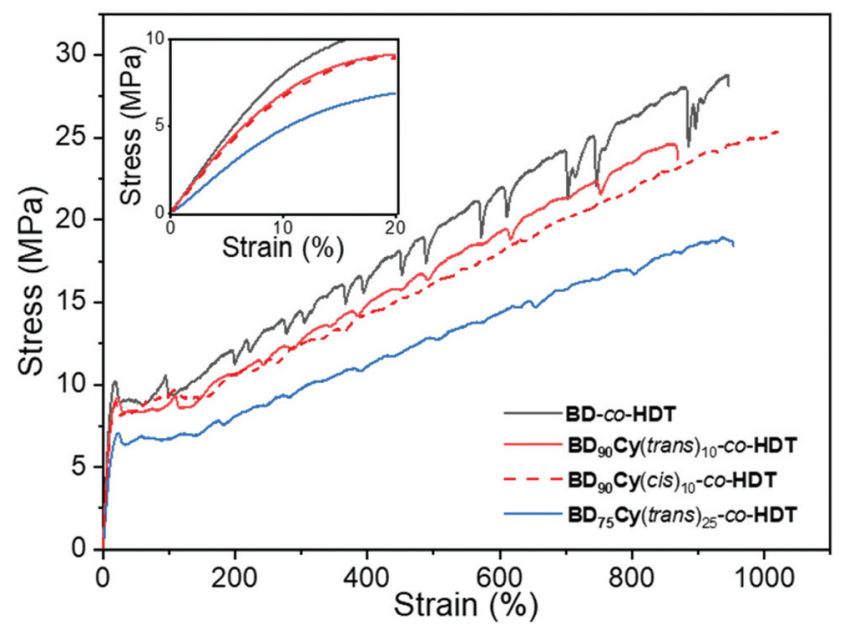

Fig. 3 Representative stress vs. strain curves of the random copolymers Inset data between 0 and $20 \%$ strain illustrating the difference in Young's modulus.

BD-co-HDT displayed the highest strength at break (UTS) and Young's Modulus $(E)$. Upon incorporation of either cyclopropane isomer: the tensile strength and Young's modulus slightly decreased. Reduction of strength and stiffness is expected as a result of cyclopropane inhibiting chain crystallisation which ultimately leads to a weaker material. Interestingly, there appeared to be negligible tensile difference between the cis and trans cyclopropane isomers at 10\% backbone content (Table S1 $\dagger$ ). Whilst this is a contrast to several previously reported cis/trans polymer systems, the low cyclopropane content within this system could inhibit the influence of stereochemistry. ${ }^{29,30}$ Further increase of the trans-cyclopropane content to $25 \%$ led to a more flexible and weaker material. $\mathbf{B D}_{75} \mathbf{C y}(\text { trans })_{25}$-co-HDT possessed an average Young's modulus of $60 \mathrm{MPa}$ in comparison to BD-co-HDT which was $105 \mathrm{MPa}$. A similar reduction in UTS was also observed between these two polymers (19.2 MPa from 29.7 MPa). This clear manipulation of tensile properties as a result of cyclopropane indicates that efforts to control polymer crystallinity were successful.

To quantify the impact of cyclopropane incorporation on polymer crystallinity in these random co-polymers, DSC analysis was performed (Fig. 4a). Incorporation of cyclopropane led to slight increases in the co-polymer $T_{\mathrm{g}}$ (Table 2). Unlike Cy (trans)-co-HDT and Cy(cis)-co-BDT, the butyl/cyclopropane random co-polymers all possessed a $T_{\mathrm{m}}$ and a $T_{\mathrm{c}}$ intuitive of a semi-crystalline material. This indicates that the large BD content was able to drive chain crystallisation within the polymer material. To quantify the extent of crystallinity, the melt transitions were normalised and integrated to obtain the total enthalpy of melting $\left(\Delta H_{\mathrm{m}}\right)$. A higher value for $\Delta H_{\mathrm{m}}$ indicates more extensive polymer crystallinity. As hypothesised, increasing the content of cyclopropane led to a lower $\Delta H_{\mathrm{m}}$ indicating a loss of crystallinity. The other striking observation of these DSC thermograms is the shift seen in the $T_{\mathrm{c}}$ to lower temperatures with an increasing cyclopropane content. Both of 
(a)

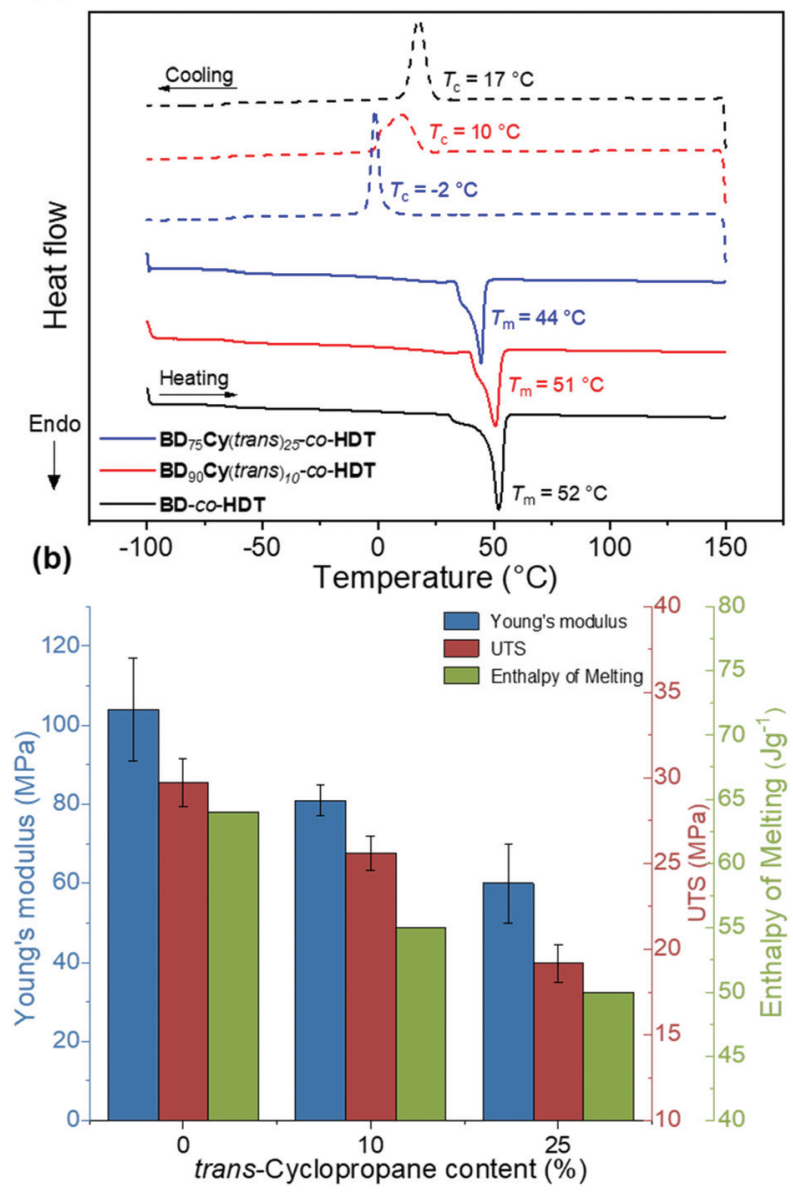

Fig. 4 (a) Normalised DSC thermograms of 2 day annealed polymers synthesised using different feed ratios of trans-cyclopropane $\mathrm{Cy}$ (trans) at a heating and cooling rate of $10 \mathrm{~K} \mathrm{~min}^{-1}$ (solid line = heating run, dashed line = cooling run). (b) Bar chart of Young's modulus (E), ultimate tensile strength (UTS) and Enthalpy of Melting vs. trans-cyclopropane content (\%) in polyester backbone.

these observations corroborate the amorphous nature of the cyclopropane structure and its ability to impede crystallinity when implemented into highly ordered polymers. This loss in crystallinity could be directly correlated with strength and Young's modulus of the resulting copolymer (Fig. 4b). Thus, the tensile properties of the polymers can not only be modulated but can be predicted from the thermal transitions.

There were minimal differences in $T_{\mathrm{g}}, T_{\mathrm{m}}$ and $\Delta H_{\mathrm{m}}$ between the cis and trans stereochemistry at $10 \%$ backbone content (Table S1†). This was expected given the comparable tensile properties of $\mathbf{B D}_{90} \mathbf{C y}(\text { trans })_{10}-\mathrm{co}-\mathbf{H D T}$ and $\mathbf{B D}_{90} \mathbf{C y}(\text { cis })_{10^{-}}-\mathrm{co}-$ HDT. However, previous investigations report that changing the cis/trans content of linear polymers led to a control of bulk crystallinity, and hence, tensile properties could be tuned. ${ }^{29,31}$ The lack of crystallinity in the initial cyclopropane-containing polymers demonstrates that neither stereochemistry promotes crystallisation. Therefore, we observe minimal differences in tensile properties between the cis and trans stereochemistry in this cyclopropane system. It was clear that controlling the content of either cyclopropane isomer in a polymer backbone led to manipulation of thermomechanical properties. Future investigation is required to understand the full extent main chain cyclopropane has on further bulk properties.

\section{Conclusion}

A polymer system has been designed to incorporate both isomers of 1,2-cyclopropane into the main chain of a polyester using nucleophilic thiol-ene addition chemistry. Cyclopropane backbones were found to be unusually amorphous. However, used as a comonomer, cyclopropane could effectively manipulate polymer crystallinity. Through the control of polymer crystallinity, it was demonstrated that Young's modulus and UTS could be decreased by $\sim 40 \%$ with as little as $25 \%$ cyclopropane content. This demonstrates an effective and simple means to control polymer crystallinity. Typically, elucidation and design of polymers with specific properties is a laborious experimental task. But through detailed understanding of structure-property relationships, design of polymers that satisfy diverse applications can be straightforward. Further study into cyclopropanes in polymers and networks are still required to understand its future potential in the synthesis of high-performance materials.

\section{Experimental}

\section{Materials}

1,6-Hexanedithiol was distilled under vacuum before use and stored under $\mathrm{N}_{2}$ in a Schlenk-flask. All other chemicals were used as received.

\section{Measurements}

All NMR experiments were performed at $298 \mathrm{~K}$ on a Bruker DPX-400 NMR instrument equipped operating at $400 \mathrm{MHz}$ for ${ }^{1} \mathrm{H}\left(100.57 \mathrm{MHz}\right.$ for $\left.{ }^{13} \mathrm{C}\right) .{ }^{1} \mathrm{H}$ NMR spectra are referenced to residual proton solvent ( $\delta 7.26$ for $\mathrm{CDCl}_{3} \delta 2.50$ for DMSO) and ${ }^{13} \mathrm{C}$ NMR spectra are referenced to the solvent signal $(\delta 77.2$ for $\mathrm{CDCl}_{3} \delta 39.52$ for DMSO). The resonance multiplicities are described as s (singlet), d (doublet), $\mathrm{t}$ (triplet), q (quartet) or $\mathrm{m}$ (multiplet).

Mass spectrometry was performed by University of Birmingham school of Chemistry on a Waters GCT Premier for compounds 2 and 3. Mass spectrometry was performed on compounds 4 and 5 using Waters Xevo G2-XS QTof.

Size Exclusion Chromatography (SEC) in THF was performed on a system composed of an Agilent 1260 Infinity II LC system equipped with an Agilent guard column (PLGel $5 \mu \mathrm{M}$, $50 \times 7.5 \mathrm{~mm}$ ) and two Agilent Mixed-C columns (PLGel $5 \mu \mathrm{M}$, $300 \times 7.5 \mathrm{~mm}$ ). The mobile phase used was THF (HPLC grade) containing $2 \% \mathrm{v} / \mathrm{v} \mathrm{NEt}_{3}$ at $40{ }^{\circ} \mathrm{C}$ at flow rate of $1.0 \mathrm{~mL} \mathrm{~min}{ }^{-1}$ (polystyrene (PS) standards used for calibration). Number average molecular weights $\left(M_{\mathrm{n}}\right)$, weight average molecular 
weights $\left(M_{\mathrm{w}}\right)$ and dispersities $\left(D_{\mathrm{M}}=M_{\mathrm{w}} / M_{\mathrm{n}}\right)$ were determined using Agilent SEC software.

Determination of the thermal characteristics of the polymers were carried out using a STARe system DSC3 with autosampler (Mettler Toledo, Switzerland). Samples were added to $40 \mu \mathrm{L}$ aluminum pans. Thermograms obtained with a heating rate of $10 \mathrm{~K} \mathrm{~min}^{-1}$ were recorded from $-100-150{ }^{\circ} \mathrm{C}$ with a $10 \mathrm{~K} \mathrm{~min}^{-1}$ heating and cooling rate over two cycles. The glass transition temperature $\left(T_{\mathrm{g}}\right)$ was determined by the minimum of the first derivative in the second heating cycle. Total enthalpy of melting $\left(\Delta H_{\mathrm{m}}\right)$ was calculated from integration and normalization of all endothermic peaks present using the STARe software.

Thermal degradation was quantified using a Q550 Thermogravimetric analyser (TA instruments). Thermograms were recorded under an $\mathrm{N}_{2}$ atmosphere at a heating rate of $10 \mathrm{~K} \mathrm{~min}^{-1}$ from $25-600{ }^{\circ} \mathrm{C}$. Decomposition temperatures were reported at the $5 \%$ weight loss temperature $\left(T_{\mathrm{d}}, 5 \%\right)$.

Thin polymer films were fabricated using a Specac Atlas ${ }^{\mathrm{TM}}$ Manual Hydraulic Press $15 \mathrm{~T}$ fitted with Specac heated plates. Films with a thickness of $0.3 \pm 0.1 \mathrm{~mm}$ were prepared by melt compressing the polymers under $c a .5 \mathrm{kN}$ of force in a hot press followed by cooling to ambient temperature in the press whilst under compression. Polymer samples were in an aluminium rectangular spacer $(20 \times 40 \times 0.5 \mathrm{~mm})$ between PTFE sheets and placed between heated plates at $90{ }^{\circ} \mathrm{C}$ unless stated otherwise and then cooled to ambient temperature maintaining $5 \mathrm{kN}$ of force. Film samples were visually inspected for deformation and bubbles before annealing for 2 days at $25^{\circ} \mathrm{C}$. Dogbones ASTM Type IV were cut out of the films and subjected to uniaxial tensile testing on a Testometric M350-5CT fitted with a load cell of $10 \mathrm{kN}$. Each specimen was clamped into the tensile holders and subjected to an elongation rate of $10 \mathrm{~mm} \mathrm{~min}^{-1}$ until failure $(n=3)$. The data was averaged, and the standard deviation is posed as the uncertainty.

Synthesis of racemic diethyl-1,2-cyclopropanedicarboxylate (1)

A dry 3-necked $1000 \mathrm{~mL}$ round bottom flask fitted with a SubaSeal ${ }^{\circledR}$, dropping funnel and gas adapter with light nitrogen flow and was then charged with sodium hydride $60 \%$ dispersion in mineral oil ( $24 \mathrm{~g}, 0.6 \mathrm{~mol}, 1.5$ equiv.) and cooled $0{ }^{\circ} \mathrm{C}$ with an ice bath. The sodium hydride was then suspended in dry toluene $(400 \mathrm{~mL})$. Ethyl acrylate $(40 \mathrm{~g}, 0.4 \mathrm{~mol}$, 1 equiv.) and ethyl chloroacetate ( $49 \mathrm{~g}, 0.4 \mathrm{~mol}, 1$ equiv.) were mixed in a beaker and charged to the dropping funnel. Approximately $5 \mathrm{~mL}$ of this mixture was added to the cooled sodium hydride solution. Nitrogen flow was increased whilst ethanol $(2 \mathrm{~mL})$ was charged via needle to the reaction whilst maintaining vessel at $0{ }^{\circ} \mathrm{C}$ with an ice bath. Once bubbling had ceased, the remaining ethyl acrylate and ethyl chloroacetate mixture was added dropwise through the dropping funnel over the course of $3 \mathrm{~h}$ to maintain the reaction temperature at $0{ }^{\circ} \mathrm{C}$. The reaction was stirred and allowed to warm to room temperature over $c a .16 \mathrm{~h}$. The reaction was quenched over crushed ice $(\sim 400 \mathrm{~mL})$ then extracted with ethyl acetate $(3 \times$ $200 \mathrm{~mL}$ ) before removal of solvent in vacuo. The remaining orange oil was distilled under vacuum to obtain a crude mixture containing title compound $(15 \%$ trans isomer and $85 \%$ cis isomer calculated by ${ }^{1} \mathrm{H}$ NMR spectroscopy) as a colourless oil (31.8 g, $170 \mathrm{mmol}, 42 \%$ overall yield). This was used as obtained in further reactions (crude NMR shown Fig. S2 $\dagger$ ). Spectral data consistent with previous work. ${ }^{32}$

\section{Synthesis of cis-1,2-cyclopropanedimethanol (2)}

A dry 3-necked $500 \mathrm{~mL}$ round bottom flask fitted with a condenser and gas adapter with light nitrogen flow was then charged with $\mathrm{LiAlH}_{4}(7.1 \mathrm{~g}, 186 \mathrm{mmol}, 1.5$ equiv.). The vessel was cooled to $0{ }^{\circ} \mathrm{C}$ and dry THF $(\sim 200 \mathrm{~mL})$ was added and stirred. A mixture of 1 (23.3 g, $125 \mathrm{mmol}, 1.0$ equiv.) in THF $(\sim 40 \mathrm{~mL})$ was added dropwise over 30 minutes. The reaction was then heated at reflux for $2 \mathrm{~h}$ and allowed to cool to ambient temperature and stirred for $c a .16 \mathrm{~h}$. The reaction was then quenched with saturated $\mathrm{NH}_{4} \mathrm{Cl}$ solution $(42 \mathrm{~mL})$ and diluted with EtOAc $(42 \mathrm{~mL})$. Remaining salts are removed by filtration and the filtrate was concentrated yielding a crude orange oil. The oil was further purified by column chromatography (100\% EtOAc) yielding title compound as a colourless oil $\left(7.3 \mathrm{~g}, 71 \mathrm{mmol}, 57 \%\right.$ yield). ${ }^{1} \mathrm{H}$ NMR $(400 \mathrm{MHz} ; 298 \mathrm{~K}$; DMSO- $d 6) \delta 4.46(\mathrm{dd}, J=6.1,4.6 \mathrm{~Hz}, 2 \mathrm{H}), 3.56(\mathrm{~m}, 2 \mathrm{H})$, 3.33-3.22 (m, 2H), 1.13-0.97 (m, 2H), $0.62(\mathrm{td}, J=8.2,4.5 \mathrm{~Hz}$, $1 \mathrm{H}), 0.11(\mathrm{~m}, 1 \mathrm{H}){ }^{13} \mathrm{C}$ NMR (101 MHz; $298 \mathrm{~K}$; DMSO- $\left.d 6\right) \delta 61.0$, 17.8, 8.2. MS (CI-TOF) calculated for $\mathrm{C}_{5} \mathrm{H}_{10} \mathrm{O}_{2} \mathrm{NH}_{4}$ 120.10; found 120.03 .

\section{Synthesis of trans-1,2-cyclopropanedimethanol (3)}

A dry 3-necked $500 \mathrm{~mL}$ round bottom flask fitted with a condenser and gas adapter with light nitrogen flow was then charged with $\mathrm{LiAlH}_{4}(3.1 \mathrm{~g}, 81 \mathrm{mmol}, 1.5$ equiv.). The vessel was cooled to $0{ }^{\circ} \mathrm{C}$ and dry THF $(\sim 60 \mathrm{~mL})$ was added and stirred. trans-Diethyl-1,2-cyclopropanedicarboxylate $(10 \mathrm{~g}$, $54 \mathrm{mmol}, 1$ equiv.) in THF ( $20 \mathrm{~mL})$ was added dropwise over 30 minutes. The reaction was then heated at reflux for $2 \mathrm{~h}$ and allowed to cool to ambient temperature and stirred for $c a$. $16 \mathrm{~h}$. The reaction was then quenched with saturated $\mathrm{NH}_{4} \mathrm{Cl}$ solution $(20 \mathrm{~mL})$ and diluted with EtOAc $(20 \mathrm{~mL})$. Remaining salts are removed by filtration and the filtrate is concentrated yielding a crude orange oil. The oil was further purified by column chromatography ( $100 \%$ EtOAc) to yield title compound as colourless oil (3.47 g, $34 \mathrm{mmol}, 63 \%$ yield) ${ }^{1} \mathrm{H}$ NMR (400 MHz, DMSO-d6) $\delta 4.37$ (d, $J=11.1 \mathrm{~Hz}, 1 \mathrm{H}), 3.35-3.23(\mathrm{~m}$, $2 \mathrm{H}), 3.26-3.14(\mathrm{~m}, 2 \mathrm{H}), 2.08(\mathrm{~s}, 1 \mathrm{H}), 0.86-0.72(\mathrm{~m}, 2 \mathrm{H})$, 0.33-0.25 (m, 2H). ${ }^{13} \mathrm{C}$ NMR (101 MHz; $298 \mathrm{~K}$; DMSO- $d 6$ ) $\delta 64.0,18.9,7.7$. Spectral data consistent with previous work. ${ }^{33}$ MS (CI-TOF) calculated for $\mathrm{C}_{5} \mathrm{H}_{10} \mathrm{O}_{2} \mathrm{NH}_{4}$ 120.1025; found 120.005.

\section{Synthesis of cis-Cy diacrylate (4)}

A 2-necked flask $100 \mathrm{~mL}$ round bottom flask fitted with a gas adapter and a dropping funnel was charged with $2(2.0 \mathrm{~g}$, 19 mmol, 1 equiv.), dry THF ( $\sim 30 \mathrm{~mL}$ ) and acryloyl chloride ( $4.4 \mathrm{~g}, 49 \mathrm{mmol}, 2.5$ equiv.). Triethylamine $(5.9 \mathrm{~g}, 59 \mathrm{mmol}$, 3 equiv.) was added dropwise slowly over the course of $1 \mathrm{~h}$ at 
$0{ }^{\circ} \mathrm{C}$ whilst stirring. The reaction was allowed to warm to ambient temperature and stirred for $c a .16 \mathrm{~h}$. The reaction was then quenched with water $(\sim 50 \mathrm{~mL})$ and was extracted with EtOAc $(3 \times 30 \mathrm{~mL})$. The organic layer was dried with $\mathrm{Mg}_{2} \mathrm{SO}_{4}$ and concentrated to an orange oil. The oil was subject to further purification by column chromatography ( $3: 1$ hexanes to ethyl acetate) yielding title compound as a colourless oil (2.3 g,11 mmol, 58\% yield). ${ }^{1} \mathrm{H}$ NMR (400 $\left.\mathrm{MHz}, \mathrm{CDCl}_{3}\right) \delta 6.41$ (dd, $J=17.3,1.5 \mathrm{~Hz}, 2 \mathrm{H}), 6.11(\mathrm{dd}, J=17.3,10.4 \mathrm{~Hz}, 2 \mathrm{H}), 5.82$ (dd, $J=10.4,1.5 \mathrm{~Hz}, 2 \mathrm{H}), 4.45-4.28(\mathrm{~m}, 2 \mathrm{H}), 4.13-3.96(\mathrm{~m}, 2 \mathrm{H})$, $1.50-1.30(\mathrm{~m}, 2 \mathrm{H}), 0.94(\mathrm{td}, J=8.4,5.3 \mathrm{~Hz}, 1 \mathrm{H}), 0.40(\mathrm{q}, J=5.6$ $\mathrm{Hz}, 1 \mathrm{H}) .{ }^{13} \mathrm{C}$ NMR (101 MHz; $\left.298 \mathrm{~K} ; \mathrm{CDCl}_{3}\right) \delta$ 166.3, 131.0, 128.6, 64.7, 14.9, 8.9. MS (CI-TOF) calculated for $\mathrm{C}_{11} \mathrm{H}_{14} \mathrm{O}_{4} \mathrm{NH}_{4}$ 228.1236; found 228.1241 .

\section{Synthesis of trans-Cy diacrylate (5)}

A 2-necked flask $100 \mathrm{~mL}$ round bottom flask fitted with a gas adapter and a dropping funnel was charged with 3 (2.0 g, 19 mmol, 1 equiv.), dry THF ( $\sim 30 \mathrm{~mL}$ ) and Acryloyl chloride (4.4 g, 49 mmol, 2.5 equiv.). Triethylamine(5.9 g, $59 \mathrm{mmol}$, 3 equiv.) was added dropwise slowly over the course of $1 \mathrm{~h}$ at $0{ }^{\circ} \mathrm{C}$ whilst stirring. The reaction was allowed to warm to ambient temperature and stirred for $c a .16 \mathrm{~h}$. The reaction was then quenched with water $(\sim 50 \mathrm{~mL})$ and was extracted with EtOAc $(3 \times 30 \mathrm{~mL})$. The organic layer was dried with $\mathrm{Mg}_{2} \mathrm{SO}_{4}$ and concentrated to an orange oil. The oil was subject to further purification by column chromatography (3:1 hexanes to ethyl acetate) yielding title compound as a colourless oil (2.1 g, $10 \mathrm{mmol}, 53 \%$ yield). ${ }^{1} \mathrm{H}$ NMR $(400 \mathrm{MHz}$, $\left.\mathrm{CDCl}_{3}\right) \delta 6.40(\mathrm{dd}, J=17.3,1.5 \mathrm{~Hz}, 2 \mathrm{H}), 6.19-6.04(\mathrm{~m}, 2 \mathrm{H})$, $5.82(\mathrm{dd}, J=10.4,1.5 \mathrm{~Hz}, 2 \mathrm{H}), 4.14-4.00(\mathrm{~m}, 2 \mathrm{H}), 4.05-3.91$ (m, 2H), 1.24-1.18 (m, 2H), 0.70-0.59 (m, 2H). ${ }^{13} \mathrm{C}$ NMR (101 MHz; 298 K; DMSO-d6) $\delta$ 166.4, 130.9, 128.6, 67.7, 16.3, 9.1. MS (CI-TOF) calculated for $\mathrm{C}_{11} \mathrm{H}_{14} \mathrm{O}_{4} \mathrm{H}$ 211.0970; found 211.0978 .

\section{General polymerisation procedure (BD-co-HDT)}

A scintillation vial was charged with 1,4-butanedioldiacrylate (0.1696 g, $0.856 \mathrm{mmol}, 1$ equiv.) and another scintillation vial was charged with 1,6-hexanedithiol (0.1285 g, $0.856 \mathrm{mmol}, 1$ equiv.). The contents of both scintillation vials were dissolved in THF (1.8 mL) and quantitatively transferred to a $25 \mathrm{~mL}$ scintillation vial and stirred at ambient temperature. Whilst stirring, polymerization was initiated with DMPP $(2.4 \mu \mathrm{L}, 2 \% \mathrm{~mol})$ and left to stir. Initially an exotherm was observed with a visible increase in viscosity. After $c a .16 \mathrm{~h}$ the polymer solution was precipitated in $\mathrm{MeOH}(100 \mathrm{~mL})$ and left to stir for $1 \mathrm{~h}$ before decanting the supernatant. Polymer was then dried under vacuum for approximately $2 \mathrm{~h}$. SEC analysis (THF $+2 \%$ $\left.\mathrm{v} / \mathrm{v} \mathrm{NEt}{ }_{3}\right) M_{\mathrm{w}}=52.7, D_{\mathrm{M}}=3.13$, DSC analysis $T_{\mathrm{g}}=-66{ }^{\circ} \mathrm{C},{ }^{1} \mathrm{H}$ NMR (400 MHz, $\left.\mathrm{CDCl}_{3}\right) \delta 4.21-4.05(\mathrm{~m}, 4 \mathrm{H}), 2.77(\mathrm{t}, J=7.5 \mathrm{~Hz}$, $4 \mathrm{H}), 2.60(\mathrm{t}, J=7.5 \mathrm{~Hz}, 4 \mathrm{H}), 2.57-2.49(\mathrm{~m}, 4 \mathrm{H}), 1.77-1.66(\mathrm{~m}$, $4 \mathrm{H}), 1.64-1.51$ (m, 6H), 1.46-1.34 (m, 4H). ${ }^{13} \mathrm{C}$ NMR (101 MHz; $\left.298 \mathrm{~K} ; \mathrm{CDCl}_{3}\right) \delta 172.2$, 64.3, 35.0, 32.3, 29.6, 28.6, 27.2, 25.5.

Cy(trans)-co-HDT. SEC analysis (THF $\left.+2 \% \mathrm{v} / \mathrm{v} \mathrm{NEt}{ }_{3}\right) M_{\mathrm{w}}=$ 38.0, $\emptyset_{\mathrm{M}}=4.30$, DSC analysis $T_{\mathrm{g}}=-52{ }^{\circ} \mathrm{C},{ }^{1} \mathrm{H}$ NMR $(400 \mathrm{MHz}$,
$\left.\mathrm{CDCl}_{3}\right) \delta 4.03-3.87(\mathrm{~m}, 4 \mathrm{H}), 2.76(\mathrm{t}, J=6.7 \mathrm{~Hz}, 4 \mathrm{H}), 2.59(\mathrm{t}, J=$ $7.3 \mathrm{~Hz}, 4 \mathrm{H}), 2.52(\mathrm{t}, J=7.2 \mathrm{~Hz}, 2 \mathrm{H}), 1.63-1.51(\mathrm{~m}, 4 \mathrm{H})$, 1.40-1.36 (m, 4H), 1.21-1.01 (m, 2H), 0.64-0.53 (t, $J=6.8 \mathrm{~Hz}$, 2H). ${ }^{13} \mathrm{C}$ NMR (101 MHz; $\left.298 \mathrm{~K} ; \mathrm{CDCl}_{3}\right) \delta 172.1,67.7,35.1$, 32.2, 29.6, 28.6, 27.1, 16.2, 9.2.

Cy(cis)-co-HDT. SEC analysis (THF $\left.+2 \% \mathrm{v} / \mathrm{v} \mathrm{NEt}_{3}\right) M_{\mathrm{w}}=37.4$, $D_{\mathrm{M}}=4.08$, DSC analysis $T_{\mathrm{g}}=-47{ }^{\circ} \mathrm{C}{ }^{1} \mathrm{H}$ NMR $(400 \mathrm{MHz}$, $\left.\mathrm{CDCl}_{3}\right) \delta 4.23(\mathrm{~m}, 2 \mathrm{H}), 4.00(\mathrm{~m}, 2 \mathrm{H}), 2.76(\mathrm{t}, J=7.5 \mathrm{~Hz}, 4 \mathrm{H})$, $2.59(\mathrm{t}, J=7.2 \mathrm{~Hz}, 4 \mathrm{H}), 2.51(\mathrm{t}, J=7.5 \mathrm{~Hz}, 4 \mathrm{H}), 1.63-1.52(\mathrm{~m}$, $4 \mathrm{H}), 1.40-1.37$ (m, 4H), 1.34-1.28 (m, 2H), 0.93-0.85 (m, 1H), $0.36(\mathrm{q}, J=5.6 \mathrm{~Hz}, 1 \mathrm{H}) .{ }^{13} \mathrm{C} \mathrm{NMR}\left(101 \mathrm{MHz} ; 298 \mathrm{~K} ; \mathrm{CDCl}_{3}\right)$ 172.1, 64.8, 35.1, 32.2, 29.6, 28.6, 27.1, 14.8, 9.0.

Cy(trans)-co-BDT. SEC analysis (THF $\left.+2 \% \mathrm{v} / \mathrm{v} \mathrm{NEt}{ }_{3}\right) M_{\mathrm{w}}=$ 23.5, $\emptyset_{\mathrm{M}}=6.58$, DSC analysis $T_{\mathrm{g}}=-17{ }^{\circ} \mathrm{C},{ }^{1} \mathrm{H} \mathrm{NMR}(400 \mathrm{MHz}$, $\left.\mathrm{CDCl}_{3}\right) 7.26$ (s, overlaps with residual $\left.\mathrm{CHCl}_{3}, 4 \mathrm{H}\right), 3.97-3.93$ $(\mathrm{m}, 4 \mathrm{H}), 3.71(\mathrm{~s}, 4 \mathrm{H}), 2.68(\mathrm{t}, J=6.6 \mathrm{~Hz}, 4 \mathrm{H}), 2.56(\mathrm{t}, J=7.4 \mathrm{~Hz}$, $4 \mathrm{H}), 1.19-1.02(\mathrm{~m}, 2 \mathrm{H}), 0.60(\mathrm{t}, J=7.4 \mathrm{~Hz}, 2 \mathrm{H}) .{ }^{13} \mathrm{C} \mathrm{NMR}$ $\left(101 \mathrm{MHz} ; 298 \mathrm{~K} ; \mathrm{CDCl}_{3}\right) \delta 172.0,137.1,129.2,129.2,67.8$, $36.1,34.7,26.5,16.2,16.2,9.2$.

BD-co-BDT. SEC analysis (THF $\left.+2 \% \mathrm{v} / \mathrm{v} \mathrm{NEt}_{3}\right) M_{\mathrm{w}}=22.0$, $D_{\mathrm{M}}=7.78$, DSC analysis $T_{\mathrm{g}}=-27{ }^{\circ} \mathrm{C},{ }^{1} \mathrm{H} \mathrm{NMR}(400 \mathrm{MHz}$, $\left.\mathrm{CDCl}_{3}\right) \delta 7.25$ (s, overlaps with residual $\mathrm{CHCl}_{3}, 4 \mathrm{H}$ ), 4.16-4.04 $(\mathrm{m}, 4 \mathrm{H}), 3.71(\mathrm{~s}, 4 \mathrm{H}), 2.68(\mathrm{t}, J=7.7 \mathrm{~Hz}, 4 \mathrm{H}), 2.55(\mathrm{t}, J=7.4 \mathrm{~Hz}$, $4 \mathrm{H})$, $1.76-1.65(\mathrm{~m}, 4 \mathrm{H}) .{ }^{13} \mathrm{C}$ NMR (101 MHz; $\left.298 \mathrm{~K} ; \mathrm{CDCl}_{3}\right)$ $\delta 172.0,137.1,129.2,64.3,36.2,34.6,26.5,25.4$.

BD $_{\mathbf{9 0}} \mathbf{C y}(\text { trans })_{\mathbf{1 0}}$-co-HDT. SEC analysis (THF $\left.+2 \% \mathrm{v} / \mathrm{v} \mathrm{NEt}_{3}\right)$ $M_{\mathrm{w}}=63.5, \emptyset_{\mathrm{M}}=4.28$, DSC analysis $T_{\mathrm{g}}=-64{ }^{\circ} \mathrm{C},{ }^{1} \mathrm{H} \mathrm{NMR}$ $\left(400 \mathrm{MHz}, \mathrm{CDCl}_{3}\right) \delta$ 4.21-4.04 (m, $\left.1.8 \mathrm{H}\right), 3.99-3.94(\mathrm{~m}$, $0.2 \mathrm{H}), 2.77(\mathrm{t}, J=7.4 \mathrm{~Hz}, 2 \mathrm{H}), 2.60(\mathrm{t}, J=7.1 \mathrm{~Hz}, 2 \mathrm{H}), 2.53(\mathrm{t}$, $J=7.3 \mathrm{~Hz}, 2 \mathrm{H}), 1.81-1.65(\mathrm{~m}, 2 \mathrm{H}), 1.62-1.58$ (m, overlapping with HDO, 2H), 1.42-1.38 (m, $J=5.4 \mathrm{~Hz}, 2 \mathrm{H}), 1.18-1.08(\mathrm{~m}$, $0.1 \mathrm{H}), 0.65-0.58(\mathrm{~m}, 0.1 \mathrm{H}) .{ }^{13} \mathrm{C}$ NMR (101 MHz; $298 \mathrm{~K}$; $\left.\mathrm{CDCl}_{3}\right) \delta 172.2,67.8,64.3,35.0,32.3,29.6,28.6,27.2$, 25.5, 16.2.

BD $_{90} \mathbf{C y}(\text { cis })_{10}$-co-HDT. SEC analysis $\left(\mathrm{THF}+2 \% \mathrm{v} / \mathrm{v} \mathrm{NEt}_{3}\right)$ $M_{\mathrm{w}}=76.9, \emptyset_{\mathrm{M}}=4.62$, DSC analysis $T_{\mathrm{g}}=-63{ }^{\circ} \mathrm{C},{ }^{1} \mathrm{H} \mathrm{NMR}$ $\left(400 \mathrm{MHz}, \mathrm{CDCl}_{3}\right) \delta 4.27-4.23(\mathrm{~m}, 0.1 \mathrm{H}), 4.17-4.09(\mathrm{~m}, 1.8 \mathrm{H})$, 4.04-3.99 (m, $0.1 \mathrm{H}), 2.77(\mathrm{t}, J=7.4 \mathrm{~Hz}, 2 \mathrm{H}), 2.60(\mathrm{t}, J=7.3 \mathrm{~Hz}$, $1 \mathrm{H}), 2.53(\mathrm{t}, J=7.9 \mathrm{~Hz}, 2 \mathrm{H}), 1.80-1.66(\mathrm{~m}, 2 \mathrm{H}), 1.65-1.48(\mathrm{~m}$, $2 \mathrm{H}), 1.40(\mathrm{t}, J=5.3 \mathrm{~Hz}, 2 \mathrm{H}), 0.96-0.87(\mathrm{~m}, 0.05 \mathrm{H}), 0.38(\mathrm{q}, J=$ $5.5 \mathrm{~Hz}, 0.05 \mathrm{H}) .{ }^{13} \mathrm{C} \mathrm{NMR}\left(101 \mathrm{MHz} ; 298 \mathrm{~K} ; \mathrm{CDCl}_{3}\right) \delta 172.1$, 64.9, 64.3, 35.0, 32.3, 29.6, 28.6, 27.2, 25.4, 14.9, 9.1.

BD $_{75} \mathbf{C y}(\text { trans })_{25}$-co-HDT. SEC analysis (THF $\left.+2 \% \mathrm{v} / \mathrm{v} \mathrm{NEt}{ }_{3}\right)$ $M_{\mathrm{W}}=91.8, \emptyset_{\mathrm{M}}=4.54, \mathrm{DSC}$ analysis $T_{\mathrm{g}}=-62{ }^{\circ} \mathrm{C},{ }^{1} \mathrm{H} \mathrm{NMR}$ $\left(400 \mathrm{MHz}, \mathrm{CDCl}_{3}\right) \delta$ 4.21-4.04 (m, $\left.1.5 \mathrm{H}\right), 3.99-3.94(\mathrm{~m}$, $0.5 \mathrm{H}), 2.77(\mathrm{t}, J=7.4 \mathrm{~Hz}, 2 \mathrm{H}), 2.60(\mathrm{t}, J=7.1 \mathrm{~Hz}, 2 \mathrm{H}), 2.53(\mathrm{t}$, $J=7.3 \mathrm{~Hz}, 2 \mathrm{H}), 1.81-1.65(\mathrm{~m}, 2 \mathrm{H}), 1.62-1.58$ (m, overlapping with HDO, 2H), 1.42-1.38 (m, $J=5.4 \mathrm{~Hz}, 2 \mathrm{H}), 1.18-1.08$ (m, $0.25 \mathrm{H}), 0.65-0.58$ (m, 0.25 H). ${ }^{13} \mathrm{C}$ NMR (101 MHz; $298 \mathrm{~K}$; $\left.\mathrm{CDCl}_{3}\right) \delta 172.2,67.8,64.3,35.0,32.3,29.6,28.6,27.2,25.5$, $16.2,9.2$.

\section{Conflicts of interest}

There are no conflicts to declare. 


\section{Acknowledgements}

This project has received funding from the European Research Council (ERC) under the European Union's Horizon 2020 research and innovation programme under grant agreement No 681559.

\section{Notes and references}

1 J. A. Galbis, M. d. G. García-Martín, M. V. de Paz and E. Galbis, Chem. Rev., 2016, 116, 1600-1636.

2 D. J. Saxon, A. M. Luke, H. Sajjad, W. B. Tolman and T. M. Reineke, Prog. Polym. Sci., 2020, 101, 101196.

3 X. Li and A. F. Yee, Macromolecules, 2003, 36, 9421-9429.

4 C.-W. Chen, C.-W. Lin, Y.-H. Chen, T.-F. Wei, S.-P. Rwei and R. Sasikumar, Polym. Bull., 2020, 77, 235-253.

5 N. Sánchez-Arrieta, A. M. de Ilarduya, A. Alla and S. MuñozGuerra, Eur. Polym. J., 2005, 41, 1493-1501.

6 X. Li and A. F. Yee, Macromolecules, 2004, 37, 7231-7239.

7 J. Wang, X. Liu, Y. Zhang, F. Liu and J. Zhu, Polymer, 2016, 103, 1-8.

8 F. Liu, J. Zhang, J. Wang, X. Liu, R. Zhang, G. Hu, H. Na and J. Zhu, J. Mater. Chem. A, 2015, 3, 13637-13641.

9 A. Celli, P. Marchese, L. Sisti, D. Dumand, S. Sullalti and G. Totaro, Polym. Int., 2013, 62, 1210-1217.

10 S.-A. Park, J. Choi, S. Ju, J. Jegal, K. M. Lee, S. Y. Hwang, D. X. Oh and J. Park, Polymer, 2017, 116, 153-159.

11 C. Lavilla and S. Muñoz-Guerra, Green Chem., 2013, 15, 144-151.

12 L. M. Lillie, W. B. Tolman and T. M. Reineke, Polym. Chem., 2017, 8, 3746-3754.

13 N. G. Moon, F. Mazzini, A. M. Pekkanen, E. M. Wilts and T. E. Long, Macromol. Chem. Phys., 2018, 219, 1800177.

14 D.-D. Xing, Y.-W. Jia, D.-F. Li, X.-L. Wang and Y.-Z. Wang, ACS Sustainable Chem. Eng., 2017, 5, 7040-7051.

15 J. Qi, J. Wu, J. Chen and H. Wang, Polym. Degrad. Stab., 2019, 160, 229-241.

16 J. C. Worch, H. Prydderch, S. Jimaja, P. Bexis, M. L. Becker and A. P. Dove, Nat. Rev. Chem., 2019, 3, 514-535.
17 R. J. Kieber, S. A. Silver and J. G. Kennemur, Polym. Chem., 2017, 8, 4822-4829.

18 A. B. Glazyrin, M. I. Abdullin, E. R. Atnabaeva, R. M. Sultanova, V. P. Volodina and V. A. Dokichev, Polym. Bull., 2019, 76, 3643-3657.

19 Á. Beltrán, B. P. Gómez-Emeterio, C. Marco, G. Ellis, M. D. Parellada, M. M. Díaz-Requejo, S. Corona-Galván and P. J. Pérez, Macromolecules, 2012, 45, 9267-9274.

20 J. Urbano, B. Korthals, M. M. Díaz-Requejo, P. J. Pérez and S. Mecking, J. Polym. Sci., Part A: Polym. Chem., 2010, 48, 4439-4444.

21 R. Oda, T. Shono, A. Oku and H. Takao, Makromol. Chem., 1963, 67, 124-131.

22 L. L. McCoy, J. Am. Chem. Soc., 1958, 80, 65686572 .

23 J. W. Chan, C. E. Hoyle, A. B. Lowe and M. Bowman, Macromolecules, 2010, 43, 6381-6388.

24 J. Vandenbergh, K. Ranieri and T. Junkers, Macromol. Chem. Phys., 2012, 213, 2611-2617.

25 A. Frick and A. Rochman, Polym. Test., 2004, 23, 413417.

26 H. Ebener, B. Pleuger and J. Petermann, J. Appl. Polym. Sci., 1999, 71, 813-817.

27 K. K. Childress, M. D. Alim, J. J. Hernandez, J. W. Stansbury and C. N. Bowman, Polym. Chem., 2020, 11, 39-46.

28 C. Wan, E. L. Heeley, Y. Zhou, S. Wang, C. T. Cafolla, E. M. Crabb and D. J. Hughes, Soft Matter, 2018, 14, 91759184.

29 C. J. Stubbs, J. C. Worch, H. Prydderch, M. L. Becker and A. P. Dove, Macromolecules, 2020, 53, 174-181.

30 Y. Yu, Z. Wei, X. Leng and Y. Li, Polym. Chem., 2018, 9, 5426-5441.

31 C. A. Bell, J. Yu, I. A. Barker, V. X. Truong, Z. Cao, A. V. Dobrinyin, M. L. Becker and A. P. Dove, Angew. Chem., Int. Ed., 2016, 55, 13076-13080.

32 R. Csuk and Y. von Scholz, Tetrahedron, 1994, 50, 1043110442.

33 W. S. McDonald, C. A. Verbicky and C. K. Zercher, J. Org. Chem., 1997, 62, 1215-1222. 